\title{
UN MODELO DE DINERO DE BANCA LIBRE ¿INFLACIONARIO O NO?
}

\author{
A model of free banking money. \\ Inflationary or not? \\ DANTE ERNESTO BAYONA*
}

Fecha de recepción: 19 de noviembre de 2020

Fecha de aceptación: 12 de marzo de 2021

\section{I}

FONDOS DEL PÚBLICO COMO PRÉSTAMO AL BANCO, NO COMO DEPÓSITO DE RESGUARDO

Toda empresa que necesita levantar fondos del público para llevar a cabo sus aventuras riesgosas tiene dos formas de hacerlo: emitir bonos o emitir acciones. Acciones y bonos representan diferentes tipos de contratos. Cuando uno adquiere acciones de una empresa, uno asume todo el riesgo y todos los posibles beneficios de la empresa; uno es propietario de la empresa. Por otro lado, cuando uno adquiere bonos de una empresa, uno otorga un préstamo a la empresa, y la empresa está obligada a devolver esos fondos, independientemente de si el negocio va bien o mal; uno es acreedor, no dueño, de la empresa. Si las aventuras riesgosas resultan positivas para la empresa, entonces los accionistas participan de ganancias relativamente mayores a las de los tenedores de bonos.

La banca de depósito parece utilizar un tercer tipo de contrato para levantar fondos, que no paga ni como bonos ni como acciones, y que lleva por nombre un tipo de contrato que ya no existe hace mucho tiempo: el contrato de depósito. El contrato de resguardo de

\footnotetext{
* Universidad Rey Juan Carlos. Email: dante.bayona@baruchmail.cuny.edu
} 
oro garantizaba la disponibilidad inmediata del oro que uno depositaba. Un certificado de depósito de oro era un recibo para reclamar el oro en cualquier momento que el depositante lo solicitase.

Hace unos pocos siglos empezaron a evolucionar y expandirse masivamente los contratos de acciones y bonos. Si bien los contratos de acciones existen desde hace muchos siglos, éstos recién empezaron a intercambiarse en mercados secundarios hace pocos siglos. Y la aparición de los estados modernos dio nacimiento a la expansión masiva de bonos de los estados que necesitaban financiamiento para las guerras. Al mismo tiempo también, el capitalismo moderno dio un gran impulso a los contratos de acciones y bonos. Pero los contratos de acciones y bonos no eran contrato de depósito, no garantizaban disponibilidad de oro. Si uno tenía oro y quería adquirir acciones, uno intercambiaba su oro por el título que le otorgaba propiedad sobre la empresa. Y si la empresa fracasaba, uno no tenía en mano un certificado para reclamar el oro que originalmente puso, sino un certificado sobre el valor residual de la empresa, fuese cual fuese dicho valor. Si la empresa fracasaba, los tenedores de bonos siempre tenían más probabilidad de recuperar sus fondos que los accionistas.

En la banca de depósito actual, los bancos levantan dinero del público para sus aventuras empresariales - otorgan préstamos a personas y negocios con diferentes niveles de riesgo- y hacen pasar esos fondos que reciben del público como contratos de depósito a la vista. Es imposible negar que los bancos usan esos depósitos en negocios riesgosos. La única forma de que los bancos no usaran esos fondos en negocios riesgosos sería que estuviesen obligados a mantener en reserva el $100 \%$ de dichos fondos. Y entonces uno puede preguntarse ¿Es correcto que los bancos arriesguen los fondos del público, como si fueran acciones y bonos, pero no los reconozcan como tal? ¿Por qué mientras a todas las empresas solo se les permite levantar dinero de dos formas, a los bancos se les permite una tercera forma? ¿Pueden los bancos justificar usar los fondos del público como acciones o bonos sin pagarles ni reconocerlos como tal, y al mismo tiempo afirmar que dichos fondos están disponibles a la vista, guardados y sin riesgo empresarial, sin mantener la reserva legal en $100 \%$ ? 
Es importante reconocer que este problema en la especificación del contrato sobre los fondos del público solo ocurre en banca de depósito, pero no en banca de inversión. En banca de inversión el banco no pretende que guarda el dinero del público en la bóveda del banco disponible a demanda. Por regulación legal estatal, el banco de inversión está obligado a colocar en toda publicidad, en el escritorio del financial advisor, en todo email, en los comerciales de televisión, etc. una prominente nota respecto al riesgo y a la posibilidad de perder los fondos. Pero nada de eso se aplica en banca de depósito. Eso debería cambiar. Si el banco no quiere reconocer al público como accionista, entonces tiene que reconocerlos como acreedores (tenedores de deuda) del banco.

Si la banca de depósito no reconoce ni paga al público como accionistas o acreedores, ni les advierte del riesgo que toman como sí hace la banca de inversión, parece pues que la banca de depósito se da de hecho un free lunch con el dinero del público. Y más aún, el gobierno subsidia el riesgo de los bancos a través del seguro gubernamental sobre los depósitos. Como socializando las pérdidas, y privatizando las ganancias. Si bien es cierto que algunas cuentas de depósito y ahorro pagan intereses, dichos intereses son insignificantes respecto a lo que se paga por bonos y acciones. $\mathrm{E}$ incluso aunque los depósitos pagaran la misma rentabilidad que bonos y acciones ¿por qué no está escrito en el contrato que son tal cosa?

Otra diferencia importante - especialmente para este paperentre los contratos de bonos y acciones, y el supuesto contrato de depósito a la vista es que, mientras los contratos de bonos y acciones prohíben ciertos actos que podrían diluir el valor de las acciones y los bonos, el contrato de depósito no pone ningún límite a la emisión de dinero-crédito - préstamos - por parte del banco, algo que naturalmente tiende a diluir el valor del dinero. El dueño de una empresa privada no puede simplemente emitir a su antojo más acciones sin antes consultar primero a los accionistas. Y la empresa que emitió bonos no puede tampoco emitir libremente más bonos poniendo en riesgo el pago a los primeros tenedores de bonos. Todo eso está especificado en el contrato. Por el contrario, en el tal llamado contrato de depósito de reserva fraccionaria no se dice nada respecto al límite en la emisión de dinero-crédito. El 
depositante no tiene voz ni voto en el asunto. El límite máximo de préstamos, que usan como base los fondos de los primeros depositantes - es decir, el riesgo máximo que puede tomar la banca de depósito- viene determinado por el permiso del gobierno sobre la reserva legal. ${ }^{1}$

El profesor Jesús Huerta de Soto ha explicado de forma completa que lo que actualmente circula como dinero no es un contrato de depósito ${ }^{2}$ lo que argumento aquí es que dicho dinero se parece más a un contrato de bonos o acciones, por el uso que los bancos dan a los fondos.

\section{II \\ BONOS COMO DINERO}

Asumamos que se produce un cambio en la ley de banca, y que la banca de depósito acepta ahora que de hecho se comporta como la banca de inversión respecto al uso de los fondos del público. Si la

${ }^{1}$ De forma simple esto viene determinado por la fórmula del multiplicador misesiano:

Préstamos = depósito inicial / reserva legal

Así, si la reserva legal es $10 \%$, entonces: $100 / 0.10=1000$

2 Ver Huerta de Soto, J. (1998): Dinero, crédito bancario y ciclos económicos, Madrid, Unión Editorial, [6ª edición, 2016].

"Siete posibilidades de calificación jurídica del contrato de depósito bancario con reserva fraccionaria

1. Hay engaño o fraude: delito de apropiación indebida y el contrato es nulo (origen históricamente viciado del depósito bancario con reserva fraccionaria).

2. No hay engaño, pero hay error in negotio: contrato nulo.

3. No hay error in negotio, pero cada parte mantiene su causa típica en el contrato: contrato nulo por tener causas esencialmente incompatibles.

4. Aunque se acepte la compatibilidad de causas incompatibles, el contrato es nulo por ser imposible su cumplimiento (si no existe un banco central).

5. Argumento subsidiario: aunque se cumpliera la «ley de los grandes números» (que no se cumple), sería un contrato aleatorio (no sería ni contrato de depósito ni de préstamo).

6. El contrato se practica en base a un mandato administrativo (privilegio) y al apoyo de un banco central que ha nacionalizado el dinero y fabrica liquidez.

7. El contrato, en todo caso, es nulo por producir graves perjuicios a terceros (crisis económicas agravadas por el banco central), muy superiores a los daños que causa el falsificador de moneda." [Pág. 126] 
banca de depósito reconociera ahora a sus clientes, por ejemplo, como acreedores del banco, no como accionistas sino como tenedores de bonos ¿qué podría utilizarse como medio de pago para transacciones en la sociedad? Si bien los títulos en papel sobre los bonos podrían empezar a circular y a ser aceptados voluntariamente, tal vez una mejor opción sería permitir escribir cheques sobre las cuentas de Money Markets, que es algo que se hacía hace unas décadas. Los Money Markets son deuda de corto plazo del banco - digamos, menos de un año. Son bonos de alta calidad. No a cualquiera se le permite emitir bonos de corto plazo, solo a las instituciones más grandes y sólidas. Así pues, los bonos de corto plazo y alta calidad constituirían un dinero privado que además de medio de intercambio serviría como reserva de valor.

Debemos observar que este tipo de medio de cambio con respaldo en bonos no constituye violación al contrato de resguardo (de oro), pero igual debe prohibirse la reserva fraccionaria sobre los bonos. Si tienes $\$ 1000$ en bonos del banco, los cheques que escribes sobre esos bonos no pueden exceder $\$ 1000$. Y el gobierno no puede permitir a los bancos emitir $\$ 2000$ de préstamos sobre solo \$1000 de bonos, como se hacía en la tal llamada época de banca libre en Estados Unidos. ${ }^{3} \mathrm{Si}$ el banco quiere emitir más crédito tiene que emitir más bonos. Y si el banco quiere emitir bonos más riesgosos, sí lo puede hacer, pero esos bonos ya no serían Money Markets, y no pueden servir de respaldo para medio de circula-

3 Ver, SOLOMON, L. (1996): Rethinking Our Centralized Monetary System, The Case for a System of Local Currencies, Westport, Praeger Publishers. Capítulo 2: "The Evolution of the U.S. Monetary and Banking System: An Overview."

"However, to open a bank, the entity generally had to buy state bonds. Free banks basically served as a scheme to sell state debt to banks. Banks were forced to hold state government debt as a share of their assets (and bank note issues) rather than being able to diversify their portfolios. Commentators recently have found that most of the bank failures occurred during periods of declining state government bond prices. When that asset depreciated in value, the banks became insolvent and suspended payments." [Pág. 9]

Ver también DUNBAR, W. (1965): Michigan, A History of the Wolverine State, Grand Rapids, William B. Eerdmans Publishing Co., [Revised edition, 1980]. Especialmente el capítulo 12: "A Cycle of Boom, Bust and Recovery." Ver también CAPIE, F; WOOD, G (1991): Unregulated Banking, Chaos or Order? New York, St. Martin's Press. Especialmente el capítulo 3: "Lessons from the American Experience with Free Banking." 
ción. Así, los proveedores de fondos deben tener voz y voto en el nivel de riesgo que desean tomar, y éste no debe estar determinado de forma arbitraria por el gobierno en conversaciones con los bancos a través de la reserva fraccionaria.

Durante la tal llamada época de banca libre en Estados Unidos, después que el presidente Andrew Jackson cerrara el segundo banco central del país, se permitía a los bancos privados emitir billetes respaldados por bonos, pero eran bonos del estado al que pertenecían, que resultaron no ser bonos de calidad 4 . En esa época los gobiernos estatales se habían embarcado en grandes proyectos de obras públicas como canales, puentes, ferrocarriles, y emitían más y más bonos. Y los bancos privados se convirtieron de facto en agentes receptores de esos bonos de dudosa calidad. Además, había reserva fraccionaria sobre esos bonos de baja calidad - es decir, el gobierno permitía a los bancos otorgar préstamos con respaldo en los bonos del estado, pero por un valor mucho mayor al valor de esos bonos en manos del banco-, y así se emitió más crédito, vino la inflación, las inversiones no resultaron tan buenas como parecían, y todo terminó en crisis. Por eso es importante tener en cuenta la calidad de los bonos que sirven de respaldo para la emisión monetaria.

Aceptar que entre en circulación este tipo de dinero-bono no implica rechazar al oro. Al contrario, esto podría abrir la puerta a la reinserción del oro en el sistema monetario, pues la gente que lo

${ }^{4}$ Ver, ROTHBARD, M (2002): A History of Money and Banking in the United States: The Colonial Era to World War II, Auburn, The Ludwig von Mises Institute:

"But the most pernicious aspect of "free" banking was that the expansion of bank notes and deposits was directly tied to the amount of state government securities that the bank had invested in and posted as bond with the state. In effect, then, state government bonds became the reserve base upon which banks were allowed to pyramid a multiple expansion of bank notes and deposits. Not only did this system provide explicitly or implicitly for fractional reserve banking, but the pyramid was tied rigidly to the amount of government bonds purchased by the banks. This provision deliberately tied banks and bank credit expansion to the public debt; it meant that the more public debt the banks purchased, the more they could create and lend out new money. Banks, in short, were encouraged to monetize the public debt, state governments were thereby encouraged to go into debt, and hence, government and bank inflation were intimately linked." [Pág. 113] 
desee podría mantener oro bajo custodia y escribir cheques sobre ese oro - manteniendo reserva de $100 \%$.

A nivel de país, el gobierno podría declarar que el dinero nacional es una combinación específica, un portafolio, de oro y bonos de cierta calidad -AAA, por ejemplo. A nivel internacional, los países podrían ajustar sus monedas a las de los otros países dependiendo de la calidad del portafolio de moneda nacional. Y así una unión monetaria entre países no requeriría la imposición forzada de una moneda como el euro. Este tipo de dinero portafolio permite superar el problema entre austriacos respecto a la reserva de $100 \%$ en oro y la emisión privada de otro tipo de dinero, pues ambos dineros pueden coexistir dentro del portafolio.

III

\section{EL DINERO-BONO Y LA INFLACIÓN}

Puede verse al dinero-bono como un dinero de libre mercado, voluntariamente aceptado como medio de cambio que también tiene un aspecto de reserva de valor. Ahora podemos pasar a analizar su función como instrumento para el cálculo económico, como unidad de cuenta estable: ¿es inflacionario?

Los defensores de la banca libre generalmente han insistido en la necesidad de que la oferta de dinero, de crédito, esté determinada por las necesidades de expansión de los negocios. Y así, han sido críticos del patrón oro por funcionar como ancla para la oferta de crédito. ${ }^{5}$ Algunos han sostenido que las letras reales constituyen una forma adecuada de incrementar la oferta de crédito, y que éstas no generan inflación pues al final de un corto periodo el crédito desaparece. Los críticos de las letras reales sostienen que sus defensores parecen asumir que el nivel de precios es una variable exógena, pero en realidad, dicen los críticos, el monto de los préstamos en letras reales está determinado no solo por el nivel de producción real que se espera sino también por el nivel de precios, que es afectado por el incremento en la oferta monetaria (el incremento

\footnotetext{
${ }^{5}$ Esto cambiaría si por alguna tecnología o descubrimiento futuro se incrementara notablemente el stock de oro existente.
} 
mismo de préstamos por letras reales). Y esto genera un mecanismo de retroalimentación inflacionario. ${ }^{6}$

Si bien los defensores de las letras reales insisten en que éstas deben ser solo de corto plazo y respaldadas por activos fuertes, en el mundo actual existe algo así como letras reales de largo plazo, a saber, las hipotecas, que claramente son inflacionarias cuando se convierten en mortgage-backed securities. La hipoteca es un préstamo que tiene como garantía un activo sólido, un activo real. Al final de 20 ó 30 años, el préstamo será devuelto y desaparecerá el crédito creado. En la práctica, los bancos se dieron cuenta que no tenían que esperar 30 años para terminar de cobrar toda la hipoteca. Hoy mismo podían vender 100 hipotecas y con ese dinero otorgar una segunda ola de préstamos. Este proceso fue originalmente desarrollado por el gobierno estadounidense que después de la depresión económica de 1929 hizo que sus agencias hipotecarias, que podían endeudarse a un interés bajo dada la protección del gobierno, empezaran a comprar los préstamos hipotecarios de los bancos, y con ese dinero que los bancos recibían pudiesen otorgar más préstamos. Décadas después varias empresas privadas empezaron a hacer lo mismo. Compraban las hipotecas, las convertían en cierto tipo de bono que vendían en el mercado de valores. Los bancos también empezaron a extender líneas de crédito a los clientes dueños de hipotecas usando como colateral la parte de la casa que ya habían pagado - Home Equity Line of Credit. Y en medio de todo esto, el

6 Ver, HUMPHREY, T (1982): «The Real Bills Doctrine», Economic Review, September/ October 1982.

"Law's Error

To summarize, Law sought a criterion that would limit money expansion and ensure price stability. He thought that land's value provided such a criterion. Collateralized by land, money could never be overissued since it would always be constrained by the value of the real property backing it. What he overlooked was that the market value of property contains a price component and that this price component is determined by the money supply itself. Since money determines the level of prices and the latter, through its influence on the value of land, is allowed to determine the size of the money stock, the result is a two-way inflationary interaction between money and prices in which both can rise without limit. That is, he failed to see that monetary expansion raises prices and that rising prices, by augmenting the nominal value of land, justifies further monetary expansion leading to further price increases and so on in a cumulative inflationary sequence." [Pág. 5] 
precio de las casas seguía aumentando dada la mayor disponibilidad de crédito para comprarlas, esto es, dada la mayor oferta de dinero-crédito para comprarlas. Es decir, también existía aquí un mecanismo de retroalimentación inflacionario.

Si bien el reconocimiento del dinero no respaldado en oro como contrato de bonos detendría la emisión sin freno de dinero-crédito por parte de los bancos como se da hoy en día - porque una empresa no puede emitir bonos y acciones a su antojo sin antes consultar a sus acreedores y accionistas, y hacerles saber sobre el riesgo que están tomando con esas nuevas emisiones- es importante analizar más en detalle si dicho dinero-bono podría contener un mecanismo de retroalimentación inflacionario.

En el actual sistema de dinero sin respaldo en oro y con reserva fraccionaria prácticamente no hay límite en la cantidad de dinero-crédito que se puede emitir; parece no haber límite en la oferta de dinero-crédito que se puede crear. El límite máximo de la oferta de dinero-crédito viene dado por el multiplicador misesiano, que en este caso establece que la cantidad total de dinero-crédito es igual a la primera base de dinero multiplicada por el inverso de la reserva fraccionaria. Esa es la máxima cantidad de dinero que los bancos pueden arriesgar. Así pues, al no haber ancla para la oferta de dinero-crédito, la cantidad de dinero-crédito tiende a estar fuertemente determinada por la demanda de crédito.

La demanda de fondos prestables, el dinero-crédito, está determinada por varios factores, pero dentro de ellos hay uno que constituye el núcleo de las finanzas modernas: la rentabilidad aumentada por apalancamiento de préstamos. La búsqueda de mayor rentabilidad por apalancamiento se observa en el mercado de acciones, de derivados, de bonos, de Forex, de hipotecas, etc.

IV

\section{LA RENTABILIDAD AUMENTADA POR APALANCAMIENTO DE DEUDA COMO DETERMINANTE DE LA DEMANDA DE FONDOS PRESTABLES}

Así como en el lado de la oferta la reserva fraccionaria genera grandes incentivos y ganancias para los bancos, pues pueden cobrar 
intereses sobre dinero que hacen aparecer de la nada - algo que a nadie más en la sociedad le está permitido-, en el lado de la demanda, el tal llamado "apalancamiento" genera grandes incentivos, y muchas ganancias (si es que todo sale bien).

Veamos en qué consiste el apalancamiento con endeudamiento de préstamos. Partamos de un caso sin apalancamiento para luego compararlo con unos casos con apalancamiento. Imaginemos que una acción de la compañía XYZ cuesta hoy, primero de enero, $\$ 100$. Yo tengo ahorrados $\$ 100$, y creo que el precio de la acción subirá. Compro una acción. Llega el final del año y la acción ha subido a $\$ 150$. Vendo la acción, y he obtenido una ganancia de 50\%. Ahora ¿qué pasa con la ganancia si uso apalancamiento pidiendo un préstamo? Digamos que, en vez de comprar una sola acción, decido comprar 5 acciones, pero como solamente tengo $\$ 100$, pido un préstamo por $\$ 400$. Llega el fin de año y la acción ha subido a $\$ 150$. Vendo las 5 acciones y recibo $\$ 750$. Pago la deuda de $\$ 400$ (además de unos cuantos intereses). Y me quedan $\$ 350$. Entonces, obtengo una rentabilidad de 250\%. ¿Qué suena mejor: una rentabilidad de $50 \%$, o una de $250 \%$ ? Esto es lo que los traders llaman comprar "en el margen", que equivale a comprar con deuda. En el mercado inmobiliario esto equivaldría a comprar 5 casas en vez de una, y luego revenderlas. Esa es la rentabilidad que se busca en Wall Street. Este mismo mecanismo de apalancamiento se usa en el mercado de opciones, y en el mercado de monedas (Forex). También se usa en el mercado de bonos. Así, la ahora infame desaparecida empresa de inversiones Long-Term Capital Management, que tenía entre sus fundadores a un ganador del premio nobel de economía, llegaba a exigir que le otorgaran préstamos con $0 \%$ de margen; eso equivaldría, en el ejemplo anterior, a comprar las 5 casas sin poner ni siquiera los $\$ 100$, un apalancamiento infinito, una rentabilidad infinita, dinero gratis ${ }^{7}$. Nótese la explosión exponencial de incentivos para pedir préstamos. Esto es un determinante cru-

7 Ver LOWENSTEIN, R. (2000): When Genius Failed, The Rise and Fall of Long-Term Capital Management, New York, Random House.

"Thus, even omitting derivatives, its leverage was greater than 100 to 1 -a fantastic figure in the annals of investment. Now, if Long-Term lost even a mere 1 percent more, it would be wiped out." [Pág. 191] 
cial de la cantidad de dinero-crédito de la economía. Es como si en el actual sistema la cantidad de dinero en la economía se determinara por la intersección de una curva de oferta perfectamente elástica y una curva de demanda de pendiente negativa (o podríamos estar incluso frente a una curva de oferta de pendiente negativa, en un modelo de equilibrio inestable, como en un modelo de especulación).

Así como el apalancamiento puede multiplicar varias veces las ganancias, también puede multiplicar varias veces las pérdidas. $\mathrm{Si}$, por ejemplo, el precio de la acción que compré pagando el monto completo de $\$ 100$ cayera a fin de año a $\$ 50$, mi rentabilidad sería de $-50 \%$; pero si hubiera comprado las 5 acciones solicitando el préstamo, entonces mi rentabilidad sería de $-250 \%$. La pérdida se multiplicó varias veces. Esto es, perdí los $\$ 100$ que puse, y a eso sumo todo lo que aún debo después de liquidar las casas a mitad de precio. En el caso de Long-Term Capital Management, si bien la rentabilidad del apalancamiento era prácticamente infinita (si todo salía bien), el riesgo también era virtualmente infinito - a menos que ellos creyeran que podían controlar matemáticamente el riesgo. Y cuando la empresa quebró a finales de los 90s tuvo que ser rescatada por el gobierno estadounidense porque había puesto en riesgo a todos los bancos que le concedieron préstamos. Los bancos fueron rescatados. Una vez más se socializaron las pérdidas y se privatizaron las ganancias. El apalancamiento es un arma de doble filo.

Así pues, tanto la oferta y demanda de dinero-crédito están fuertemente determinadas por estos multiplicadores y aceleradores de crédito, de ganancias y riesgo.

El asunto de que las empresas financieras tiendan a sobre endeudarse para lograr mayores ganancias con apalancamiento no es un asunto nuevo, por eso desde hace mucho los agentes reguladores les han impuesto límites sobre el nivel de deuda, relativo al nivel de capital propio, que pueden mantener. A eso se le conoce como requerimientos de capital. Así como los reguladores exigen que la banca de depósito mantenga cierto nivel de depósitos en reserva para hacer frente a las corridas bancarias, los reguladores también exigen a las entidades financieras mantener niveles mínimos de capital propio para hacer frente a los tiempos difíciles. 
El inverso del requerimiento de capital funciona como un multiplicador de crédito - similar al multiplicador de Mises en banca de depósito. Mientras más bajo sea el requerimiento, más puede endeudarse una empresa -más de sus activos puede usar como colateral para pedir préstamos. En la crisis del 2008 los bancos de inversión más tóxicos del sistema estaban sobreapalancados entre 30 y 50 veces su capital. ${ }^{8}$ Y si bien una empresa puede utilizar sus activos como colateral para deuda de largo plazo, los traders de la crisis del 2008 estaban sobre apalancados para especulación de muy corto plazo. Es decir, los bancos tenían carta blanca para imprimir miles de millones de dólares para actividades extremadamente riesgosas - lo opuesto a tratar de financiar esas actividades con bonos de alta calidad. Los bancos podrían tal vez ser libres

8 Ver, MCDONALD, L; ROBINSON, P. (2009): A Colossal Failure of Common Sense, The Inside Story of the Collapse of Lehman Brothers, New York, Crown Business, New York.

"Not to mention the fact that Lehman Brothers was well on the way to being leveraged to forty-four times our value - that's well north of $\$ 700$ billion. We were somehow out there buying wildly overpriced skyscrapers with distant views to the friggin' Eiffel Tower, still buying hedge funds. And we were still up to our ears in apartments-we probably owned more than two hundred thousand of them worldwide. [Pág. 263]

[...] David's presentations should be read by every would-be Wall Street trader, analyst or investment banker. 'The problem with 44 times leverage is that, if your assets fall in value by only I percent, that's half your real tangible equity. Remember Lehman only had $\$ 15$ billion. Multiply that by 44 and you have $\$ 660$ billion. Drop that by 1 percent and that's $\$ 6.6$ billion. Right then that 44 times leverage becomes 80 percent. And all confidence is lost." [Pág. 287]

En mayo del 2010, Reuters reportó sobre Bear Stearns: Bear Stearns' Cayne concedes leverage was too high:

"The former Bear Stearns executives were grilled over whether the investment bank's leverage level and lack of foresight on a looming collapse of the U.S. mortgage market made it the first major victim of the financial crisis.

Angelides said by the end of 2007, Bear was leveraged 38-to-one, when measured in terms of tangible assets versus tangible common equity."

Considérese además la confesión de Alan C. Greenberg, ex-chairman de Bear Stearns en su libro The Rise and Fall of Bear Stearns (2010):

"Without leverage, it would have been impossible for us, or anyone else, to accumulate the debt assets that we then so lucratively securitized. Under the circumstances, on occasions when I voiced my customary skepticism I didn't really have a chorus backing me up." [Pág. 137] 
para emitir bonos de mediano y largo plazo de diferente calidad colateralizados con activos de diferente calidad, pero eso no podría usarse como respaldo de un medio de cambio.

Así pues, mientras la reserva fraccionaria en banca de depósito expande la cantidad de dinero, la reserva fraccionaria en requerimientos de capital también expande la cantidad de dinero-crédito dependiendo del nivel que establezcan los reguladores, o de una supuesta autorregulación de la entidad financiera.

Ahora, regresando al tema de este paper, si se usara un dinero-bono, manteniendo el $100 \%$ de reserva sobre los cheques que se escriben sobre los bonos, un requerimiento de capital de menos de $100 \%$ podría tal vez seguir multiplicando los préstamos y la cantidad de dinero. Así podemos imaginar una situación en que los bancos estén dispuestos a emitir más bonos para financiar a empresas que solicitan préstamos poniendo como garantía colateral los activos de buena calidad de dicha empresa. El asunto ahora sería ver si esos bonos deberían usarse para emitir dinero o no.

¿Valdrá la pena usar bonos de largo plazo (de buena calidad) como base para escribir cheques? Imaginemos que un banco cree que es buen negocio otorgar préstamos hipotecarios, porque considera que es casi seguro que todos los préstamos serán devueltos. Y decide levantar fondos del público emitiendo bonos para financiar esos proyectos. ¿Cómo saber si esas hipotecas son realmente un buen negocio o simplemente son una euforia colectiva, un exceso de optimismo? Si bien es cierto que la casa que sirve de colateral a la hipoteca es un activo real ¿será suficientemente buen activo, o tendrá un falso valor de mercado debido a un proceso de retroalimentación inflacionario?

Nótese la diferencia entre una euforia colectiva por invertir en la construcción de casas que sirven como garantía colateral, y la euforia colectiva de la crisis de las puntocom donde todos apostaban por una nueva tecnología sin ningún colateral. Es importante notar que, en el primer caso, igual que en las letras reales, estamos hablando de un préstamo colateralizado por activos. Y no olvidemos la poca conveniencia de los préstamos de largo plazo como base de emisión de dinero, que como vimos anteriormente pueden generar un mecanismo de retroalimentación inflacionario.

Por tanto, incluso si se regresara al patrón oro con reserva de $100 \%$, pero se mantuviera reserva fraccionaria en requerimientos 
de capital en menos de 100\%, y los bancos fueran libres de emitir dinero según "las necesidades de los negocios" usando como colateral activos supuestamente seguros pero de largo plazo, el sistema aún podría generar ciclos económicos. ${ }^{9}$ Entonces, la primera recomendación es no usar deuda de largo plazo para emitir un medio de intercambio.

Ahora podemos preguntarnos ¿Además de solo permitir la emisión de dinero sobre la base de bonos de buena calidad de corto plazo, puede hacerse algo más que evite o controle una excesiva expansión de crédito?

Lo que tiene que buscarse es que la oferta de dinero se determine de forma exógena, que esté atada al mundo económico real de la escasez, que esté atada a algo externo como el oro. Posiblemente por eso Adam Smith, si bien permitía las letras reales, exigía la convertibilidad en oro de todo el dinero, incluido el dinero respaldado en activos reales. Así que aquí aparece otra defensa para el patrón oro: no se trata de exigir reserva de $100 \%$ solo para hacer cumplir el contrato de resguardo de oro en banca de depósito, sino también como ancla para todo dinero-crédito que se pueda generar, para imponer un límite máximo al riesgo que los bancos pueden tomar. Solo así se puede evitar el mecanismo de retroalimentación inflacionario sin freno. ${ }^{10}$

Si la convertibilidad obligatoria en oro no es una opción, una alternativa de ancla sería prohibir legalmente la toma excesiva de

9 Así, la tercera versión de los acuerdos de Basilea, después de la crisis del 2008, se ha concentrado ya en reforzar la calidad de los activos empleados como reserva de capital, y en incrementar el porcentaje de reserva.

${ }^{10}$ Ver HUMPHREY, T (1982): «The Real Bills Doctrine», Economic Review, September/October 1982.

"While endorsing the doctrine, however, Smith managed to avoid some of its shortcomings. He realized, for example, that the real bills criterion by itself is not sufficient to prevent overissue. For that reason, he advocated specie (i.e., gold) convertibility as the ultimate constraint on the quantity of paper money. That is, he held that banks should be required by law to convert their paper notes into specie at a fixed price upon demand. Constrained by the convertibility obligation, banks, he felt, would rarely overissue. In short, he viewed specie convertibility as the overriding check to overissue. In so doing, he avoided the error of supposing that the real bills criterion per se provides a sufficient limitation to the note issue regardless of the monetary regime." [Pág. 8] 
riesgo, algo así como prohibir las apuestas en banca. Esta forma ya existe en banca islámica. La banca islámica además de ser banca de reserva de $100 \%$ en oro, también prohíbe la toma excesiva de riesgo, es decir, parece abarcar ambos aspectos del asunto: por un lado, anclando la oferta de dinero al oro, por otro lado, prohibiendo la toma de riesgo excesivo. Así pues, cuando uno quiere comprar una casa y va al banco islámico por una hipoteca, el banco no le da a uno una chequera de reserva fraccionaria para pagar por la casa, el banco compra la casa con el dinero del banco mismo, y luego uno le paga al banco poco a poco, con un margen de ganancia. No hay expansión de dinero-crédito. $Y$ dado que las apuestas de alto riesgo también están prohibidas en el islam, los derivados financieros más riesgosos también están prohibidos. ${ }^{11}$

Si lo anterior no es suficiente, se podría también aplicar una tasa impositiva a toda expansión secundaria de dinero.

La alternativa más estricta para restringir la emisión de dinero - haciendo un paralelo con la reserva de $100 \%$ en oro- sería exigir una reserva de $100 \%$ en los requerimientos de capital, algo así como prohibir que las empresas utilicen sus activos propios como garantía colateral para pedir préstamos, y que solo puedan levantar dinero directamente del público a través de bonos y acciones. ¿Será esa la solución? ${ }^{12}$

${ }^{11}$ Los libros de banca islámica ya explican cómo funcionan las tarjetas de crédito, los préstamos para autos, las hipotecas, y otros productos financieros bajo los requerimientos antes explicados. Y solamente se permite hacer dinero con participación o deuda (acciones y bonos). Ver, IQBAL, M; LLEWELLYN, D. (editores) (2002): Islamic Banking and Finance, New Perspectives on Profit-Sharing and Risk, Cheltenham, Edward Elgar.

12 De hecho, el economista Hernando de Soto sostiene que el tercer mundo en parte es pobre porque no utiliza el capital ahorrado como garantía para préstamos. Ver, El Misterio del Capital (2000):

"Pero se trata de una posesión defectuosa: las casas de los pobres están construidas sobre lotes con derechos de propiedad inadecuadamente definidos, sus empresas no están constituidas con obligaciones claras y sus industrias se ocultan donde los financistas e inversionistas no pueden verlas. Sin derechos adecuadamente documentados, estas posesiones resultan activos difíciles de convertir en capital, no pueden ser comercializados fuera de los estrechos círculos locales donde la gente se tiene confianza mutua, no sirven como garantía para un préstamo ni como participación en una inversión. 
Hasta el momento hemos estado hablando de un dinero respaldado directamente por bonos, pero en teoría también podría estar respaldado por acciones de un fondo abierto que invierte en bonos de alta calidad. Abierto en el sentido de que puede aumentar y reducir el número de acciones como necesite. Como cierto tipo de Money Market Fund, que mantenga constante el valor neto de los activos del fondo día tras día. Para mantener el status de Money Market Fund dichos fondos invierten en valores de alta calidad, muy líquidos y de corto plazo. ${ }^{13}$ Así, un banco que quiera levantar fondos del público puede utilizar este tipo de fondos, que es más elástico desde la perspectiva del banco, y sobre esas acciones del fondo podrían escribirse cheques. Igual que anteriormente, si ese fuese el caso, uno puede imaginar una situación en que un exceso de optimismo lleve a una mayor emisión de acciones del fondo, y esto a una mayor emisión de dinero-acción.

\section{CONCLUSIÓN}

No es la primera vez que una moneda con respaldo en un activo diferente al oro es planteada. En 1705 John Law expuso la idea de una moneda respaldada por el valor de la tierra, sin entender el mecanismo de retroalimentación inflacionario, ni el multiplicador

En Occidente, en cambio, toda parcela de tierra, toda construcción, toda pieza de equipo o depósito de inventarios está representado en un documento de propiedad que es el signo visible de un vasto proceso oculto que conecta a tales recursos con el resto de la economía. Gracias a este proceso de representación, los activos pueden llevar una vida paralela a su existencia material. En tal condición pueden ser usados como garantía para crédito. La mayor fuente individual de recursos para nuevos negocios en Estados Unidos es la hipoteca sobre la casa del empresario. Estos activos también pueden aportar un nexo con la historia crediticia del propietario, dar un domicilio asequible para la cobranza de deudas e impuestos, ser una plataforma para la creación de servicios públicos confiables y universales, y una base para crear valores (por ejemplo, bonos con respaldo hipotecario) que luego puedan ser redescontados y vendidos en mercados secundarios. Así, mediante este proceso, Occidente inyecta vida a sus activos y los hace generar capital."

13 Ver, Money Market Funds, Securities and Exchange Commission, www.sec. gov/spotlight/money-market.shtml 
misesiano del crédito como causa del ciclo económico. Y el poco calculado experimento terminó en la burbuja del Mississippi y en la destrucción de la economía francesa. El oro seguía siendo el mejor freno absoluto para la expansión de todo tipo de dinero emitido por los bancos. Al rededor de la misma época empezaron a aparecer confusiones sobre el contrato de depósito, y el problema se mantiene hasta nuestros días.

El análisis de Mises del efecto multiplicador de la reserva fraccionaria sobre el dinero-crédito es un instrumento muy importante para analizar lo que ocurre en la economía en su conjunto. Así pues, en este paper nos ha servido para analizar el impacto de cambios en la relación deuda-capital que los reguladores permiten a las empresas mantener al momento de solicitar préstamos. Los reguladores usan los requerimientos de capital como una medida de control de riesgo para los bancos. La alternativa lógica a la supervisión gubernamental de los reguladores es que todo el riesgo sea asumido de forma privada, y eso debería lograrse a través de la emisión de bonos $\mathrm{y}$ acciones con el riesgo correspondiente.

Encontramos que si se permitiera escribir cheques sobre bonos de largo plazo (incluso manteniendo el 100\% de reserva sobre los bonos) colateralizados con activos de buena calidad de la empresa - es decir, bajo un sistema de requerimientos de capital de menos de $100 \%$ en reserva - el sistema tendería a ser más inflacionario que si solo se permitiera escribir cheques sobre bonos de corto plazo de buena calidad, pues sería más difícil controlar las euforias colectivas de optimismo.

¿Será necesario exigir 100\% de reserva en requerimientos de capital para frenar por completo los ciclos económicos? ¿Será que un país pobre solo puede desarrollarse regresando al patrón oro? ¿Podría afirmarse que toda emisión de dinero sin respaldo en oro termina en catástrofe? Tal vez no. Es muy posible que China nunca hubiera podido salir de la pobreza sin emitir dinero sin respaldo en oro. Pero el dinero de China tenía un respaldo real, esto es, la producción real que el mundo compraba. Tal vez China, como un todo, solo estaba imprimiendo trillones de acciones y bonos colateralizados con su producción real.

El estudio de las acciones y bonos debería tal vez estar más presente en el estudio austriaco del ciclo económico. Acciones y bonos 
tienen un mismo origen en la necesidad de crédito de las empresas. Una superemisión de bonos y acciones estuvo presente a comienzos del boom de los ferrocarriles que terminó en el pánico de 1873 en Estados Unidos, Austria y Londres. Estuvo presente en el pánico de 1907. Definitivamente estuvo presente en el crash del 29. Se manifestó en los 80 s en la superemisión de bonos chatarra -lo opuesto a bonos AAA - que terminó en la crisis que destruyó las cajas de ahorro de Estados Unidos. Estuvo presente en la crisis de las puntocom. Y estuvo presente en el crash del 2008.

El análisis del dinero-bono como medio de cambio y reserva de valor puede servir de referencia al momento de analizar cierto tipo de dinero que solo parece ser medio de cambio, pero no reserva de valor, por ejemplo: Bitcoin. Si bien la oferta de Bitcoin parece determinarse de forma exógena, no está ligada a reserva de valor. Reserva de valor se necesita por la incertidumbre del mundo económico. Tal vez si alguien registrara su casa como propiedad usando el Blockchain podría utilizar ese título como medio de pago, pero eso carece de medida estándar, carece de uniformidad y liquidez. Los bancos no aceptan cualquier cosa como garantía para un préstamo, solo aceptan como colateral cosas que ellos creen podrán vender económicamente si el proyecto empresarial fracasa. Parece que el hecho de no expandirse según las necesidades de los negocios es lo único que Bitcoin ha claramente heredado del oro. Pero el oro ha visto el fracaso de todos los imperios de la historia. Todas las veces que la historia regresó a cero, el oro estuvo allí para cubrir la incertidumbre.

\section{REFERENCIAS BIBLIOGRÁFICAS}

Capie, F; Wood, G. (editores), (1991): Unregulated Banking, Chaos or Order? New York, St. Martin's Press.

De Soto, H. (2000): El misterio del capital, Lima, Editorial Planeta [Primera edición digital, 2019].

Dunbar, W. (1965): Michigan, A History of the Wolverine State, Grand Rapids, William B. Eerdmans Publishing Co., [Revised edition, 1980]. 
Greenberg, A (2010): The Rise and Fall of Bear Stearns, New York, Simon \& Schuster.

Huerta de Soto, J. (1998): Dinero, crédito bancario y ciclos económicos, Madrid, Unión Editorial, [ $7^{\mathrm{a}}$ edición, 2020].

Humphrey, T (1982): «The Real Bills Doctrine», Economic Review, September/ October 1982, pp. 3-13.

Iqbal, M; Llewellyn, D. (editores) (2002): Islamic Banking and Finance, New Perspectives on Profit-Sharing and Risk, Cheltenham, Edward Elgar.

Lawder, D; Younglai, R (2010): «Bear Stearns' Cayne concedes leverage was too high», Reuters. www.reuters.com/article/us-financial-regulation-bearstearns/bear-stearns-cayne-concedesleverage-was-too-high-idUSTRE64420N20100505

Lowenstein, R. (2000): When Genius Failed, The Rise and Fall of LongTerm Capital Management, New York, Random House.

Mcdonald, L; Robinson, P. (2009): A Colossal Failure of Common Sense, The Inside Story of the Collapse of Lehman Brothers, New York, Crown Business, New York.

Rothbard, M (2002): A History of Money and Banking in the United States: The Colonial Era to World War II, Auburn, The Ludwig von Mises Institute.

Solomon, L. (1996): Rethinking Our Centralized Monetary System, The Case for a System of Local Currencies, Westport, Praeger Publishers. 